www.jmscr.igmpublication.org

Impact Factor 5.84

Index Copernicus Value: 71.58

ISSN (e)-2347-176x ISSN (p) 2455-0450

crossref DOI:_https://dx.doi.org/10.18535/jmscr/v5i11.218

Journal Of Medical Science And Clinical Research

\title{
Supraclavicular lymphadenopathy: Cytopathological study of 3 years with Review of Literature
}

\author{
Authors \\ Sujata R. Kanetkar ${ }^{1}$, Dhirajkumar B. Shukla ${ }^{2}$, Pradnya P. Kale ${ }^{3}$, Atul B. Hulwan ${ }^{3}$ \\ ${ }^{1}$ Professor and Head, Department of Pathology, Krishna Institute of Medical Sciences, Karad \\ ${ }^{2}$ Assistant Professor, Department of Pathology, Krishna Institute of Medical Sciences, Karad \\ ${ }^{3}$ PG student, Department of Pathology, Krishna Institute of Medical Sciences, Karad \\ Corresponding Author
}

Dr Dhirajkumar B.Shukla

Assistant Professor, Department of Pathology, Krishna Institute of Medical Sciences, Karad.

Email: drshukla.patho@gmail.com

\begin{abstract}
Background: Fine needle aspiration cytology of enlarged lymph nodes has evolved as a first line of investigation in diagnosis of spectrum of lesions. Supraclavicular Lymphadenopathy can be due to many pathological conditions such as tuberculosis, primary malignancy and also due to metastasis from various primary malignancies. The aim of the study was to analyze spectrum of diseases in cases with supraclavicular lymphadenopathy using Fine needle aspiration cytology and its utility in diagnosis.

Material \& Methods: Present study is a prospective study carried over a period of three years from June 2012 to May 2015. Fine needle aspiration was performed on 54 cases presenting as supraclavicular lymphadenopathy, referred to Department of Pathology.

Results: Out of 54 cases of supraclavicular lymphadenopathy from different clinicians were studied. Out of 54 cases $30(55.55 \%)$ cases were of Right sided lymphadenopathy and 24(44.44\%) were of left with no bilaterally in even single case. The study showed female predilection with $36(66.66 \%)$ cases \& $18(33.33 \%)$ were male patients. The age ranged from 3 months to 78 years with different pathological diagnosis. Cytological diagnosis were categorized as Metastatic malignancy in 24 cases Reactive lymphadenitis (11/54), Acute suppurative lymphadenitis (11/54), and Granulomatous lymphadenitis in 8 cases with single case having tubercular bacilli on $20 \%$ ZN staining. Out of 24 cases of metastasis major types found were adenocarcinoma, squamous cell carcinoma, anaplastic carcinoma of thyroid, carcinoma of breast. Adenocarcinoma had tendency to metastasis to Left side.

Conclusion: Supraclavicular lymphadenopathy suggests some underlying pathology in young as well as old patients. The study emphasizes on importance, utility, simplicity of fine needle aspiration in diagnosis of such cases.
\end{abstract}

\section{Introduction}

In recent times, Fine Needle Aspiration Cytology (FNAC) has evolved as an important tool in the diagnosis of various diseases. FNAC being minimally invasive, tolerable, safe and cost effective procedure is investigation of choice for evaluating the cause of the disease. ${ }^{1}$ Many studies have shown the utility of FNAC in diagnosing the cause of lymphadenopathy with high sensitivity 
and specificity. ${ }^{2-5}$ Supraclavicular lymph node being easily palpable, and favorable site for metastasis is known as "Sentinel Node". 6 Left supraclavicular lymph node also known as Virchow's node, also known as "Virchow's Node" is common site of distant metastasis from malignancies from abdomino-pelvic organs such as gastric malignancy etc. ${ }^{7}$ Enlarged Supraclavicular being easily palpable, hence FNAC can yield the diagnosis. The present study is undertaken to know the disease pattern encountered in cases of supraclavicular lymphadenopathy using FNAC. The study further emphasizes the utility of FNAC as the first line of investigation for the evaluation of palpable supraclavicular lymphadenopathy.

\section{Material \& Methods}

This is a prospective, observational \& analytical study carried out in Department of Pathology over a period of 3 years (June 2012 to May 2015). All the cases with supraclavicular lymphadenopathy subjected to FNAC examination were studied. Cases in which aspiration was inadequate were excluded from the study.

Clinical details were recorded in predefined proforma. Clearance from institutional ethics committee was obtained. FNAC was performed after taking consent from the patient and in cases of paediatric patient consent was taken from parents. Smears were routinely stained with Haematoxylin \& Eosin, Giemsa and special stains applied wherever needed. Standard guidelines for cytological diagnosis were followed. ${ }^{8}$ Results were grouped as nonspecific reactive lymphadenitis (NSRL), acute suppurative lymphadenitis, tuberculosis ( $\mathrm{Tb})$, and metastatic lymphadenopathy.

Their pattern of distribution was assessed according to patient's age, sex, and side of involvement.

\section{Result}

Total 54 patients with supraclavicular lymphadenopathy were subjected to fine needle aspiration cytological examination over the period of 3 years. The age of the patients ranged from 3 months to 78 years. Youngest patient subjected to FNAC was 3 month old child and eldest was 78 year old male. The mean age was 48.6 years. (Table 1) Majority of the cases were above the age of 40 years.(Table 1)

Table No. 1: Age wise distribution of the cases.

\begin{tabular}{|l|c|}
\hline Age in years & No. of cases \\
\hline$<10$ & 2 \\
\hline $11-20$ & 1 \\
\hline $21-30$ & 6 \\
\hline $31-40$ & 12 \\
\hline $41-50$ & 9 \\
\hline $51-60$ & 12 \\
\hline $61-70$ & 10 \\
\hline $71-80$ & 2 \\
\hline Total & 54 \\
\hline
\end{tabular}

Varieties of lesions were encountered in these 54 cases of supraclavicular lymphadenopathy. Most common finding was metastatic lesion with 24 out of 54 cases (Table 2). Metastatic lesions were found predominantly in patients above 40 years of age (Table 3).

Table No. 2: Different diagnosis with number of cases with percentage in each.

\begin{tabular}{|l|c|c|}
\hline Diagnosis & No. of cases & Percentage \\
\hline Metastasis & 24 & 44.44 \\
\hline Reactive lymphadenitis & 11 & 20.37 \\
\hline $\begin{array}{l}\text { Suppurative } \\
\text { lymphadenitis }\end{array}$ & 11 & 20.37 \\
\hline Granulomatous & 08 & 14.82 \\
\hline Total & 54 & 100 \\
\hline
\end{tabular}

Table No. 3: Age wise distribution of cases on the basis of diagnosis

\begin{tabular}{|l|c|c|c|c|c|}
\hline Age & Mets & $\begin{array}{c}\text { Granulo } \\
\text { matous }\end{array}$ & Reactive & $\begin{array}{c}\text { Acute } \\
\text { suppurative }\end{array}$ & Total \\
\hline$<=10$ & 0 & 1 & 0 & 1 & 2 \\
\hline $11-20$ & 0 & 1 & 0 & 0 & 1 \\
\hline $21-30$ & 0 & 1 & 4 & 1 & 6 \\
\hline $31-40$ & 4 & 2 & 3 & 3 & 12 \\
\hline $41-50$ & 6 & 1 & 0 & 2 & 9 \\
\hline $51-60$ & 9 & 0 & 2 & 1 & 12 \\
\hline $61-70$ & 4 & 2 & 1 & 3 & 10 \\
\hline $71-80$ & 1 & 0 & 1 & 0 & 2 \\
\hline & 24 & 8 & 11 & 11 & 54 \\
\hline
\end{tabular}

Most of the cases were noted in females with male to female ratio being 1:2.Metastatic lesion showed inclination towards female with 20 out of 24 cases being female (Table 4). 


\section{JMSCR Vol||05||Issue||11||Page 31078-31084||November}

Table No. 4: Sex wise distribution of cases on the basis of diagnosis

\begin{tabular}{|l|c|c|c|}
\hline Diagnosis & Males & Females & Total \\
\hline Metastasis & 4 & 20 & 24 \\
\hline Reactive lymphadenitis & 4 & 7 & 11 \\
\hline Acute lymphadenitis & 7 & 4 & 11 \\
\hline Granulomatous & 3 & 5 & 08 \\
\hline Total & 18 & 36 & 54 \\
\hline
\end{tabular}

Most common metastatic lesion noted was adenocarcinoma (Figure 1) (20/24), followed by 3 cases of squamous cell carcinoma (Figure 2) anda single case of plasmacytoma. Breast was the most common primary site with 9 cases of metastatic lesion in supraclavicular lymphnode, followed by metastasis from Gastro-intestinal tract constituting 4 cases (Table 5). Carcinoma ovary (Figure 3) was primary site in 3 cases whereas metastatic thyroid carcinoma (Figure 4) was noted in 2 cases. Metastatic adenocarcinoma from lungs and prostate was notedin one case each.

Metastatic squamous cell carcinoma was noted in 3 cases with tonsil, cervix, and lung being the primary site in 1 case each. Metastasis from plasmacytoma was noted in 1 case. Left sided supraclavicular lymph node was commonly involved (14/24).

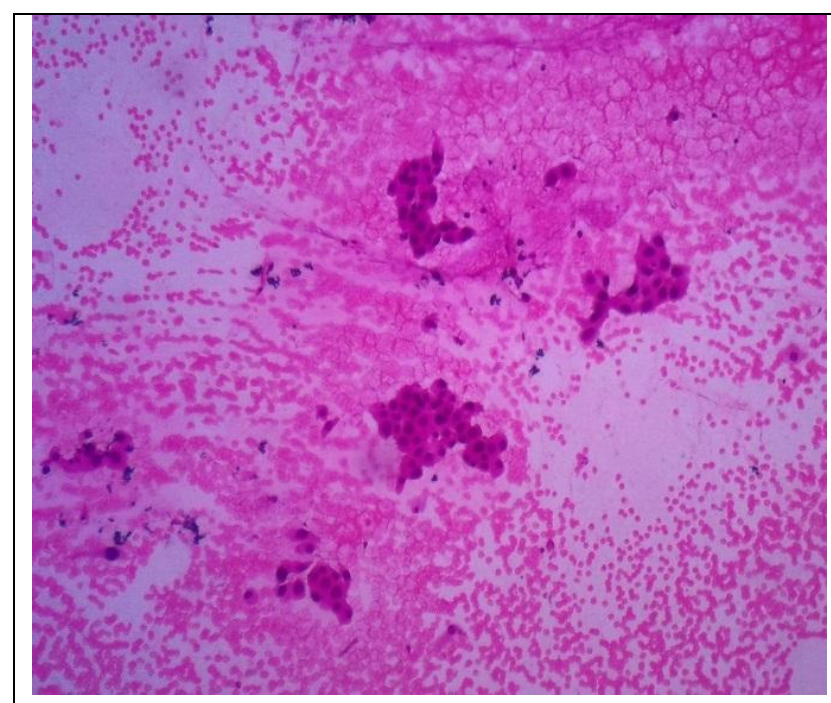

Figure 1. Photomicrograph of FNAC SCLN showing Metastatic Adenocarcinoma (100 x, $\mathrm{H} \& \mathrm{E})$

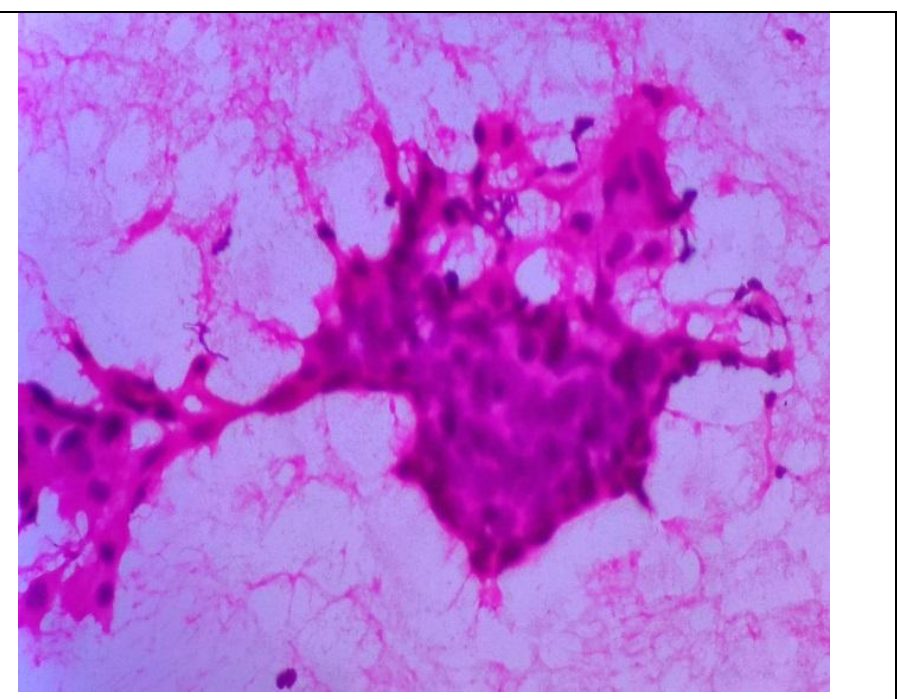

Figure 2. Photomicrograph of FNAC SCLN showing Metastatic Squamous cell carcinoma (100 x, H\&E)

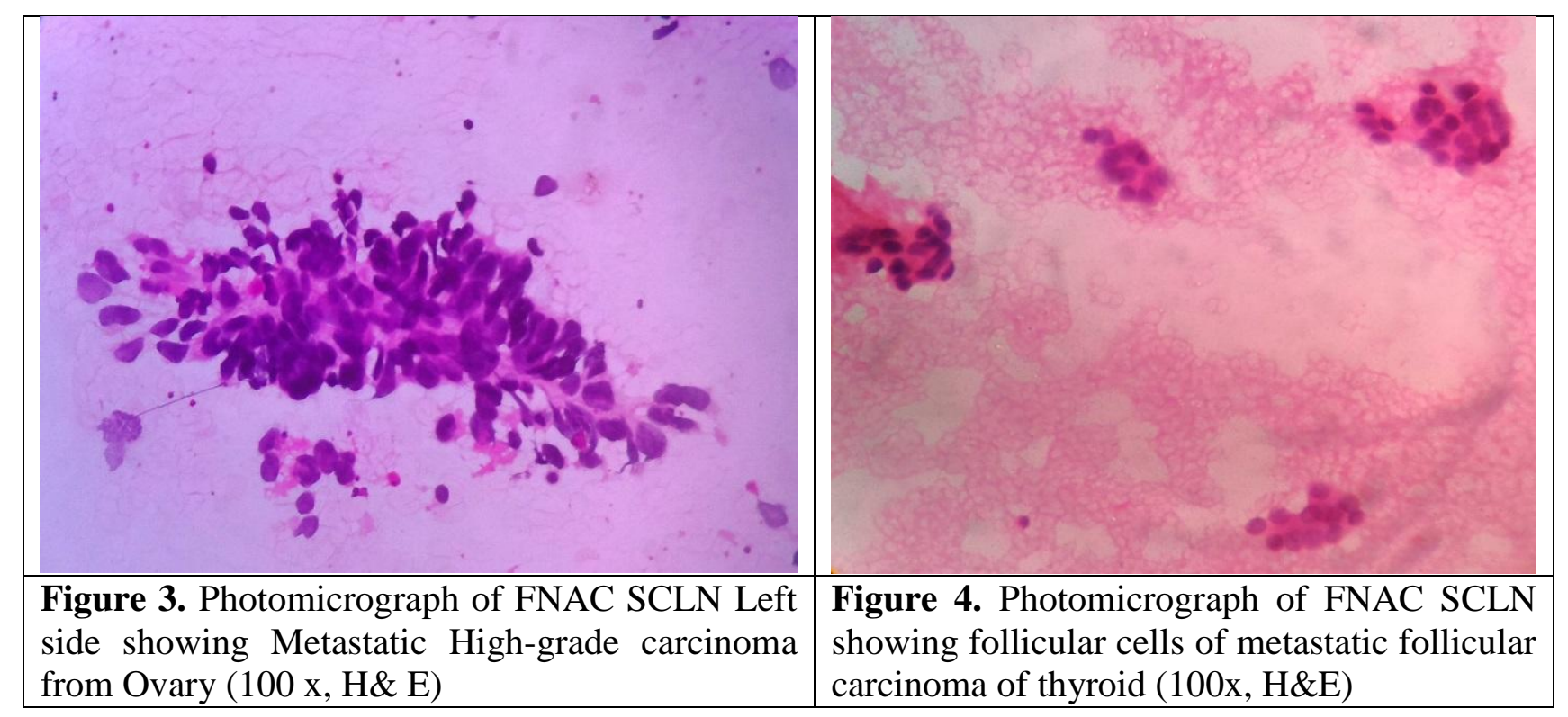




\section{JMSCR Vol||05||Issue||11||Page 31078-31084||November}

Table No. 5: Distribution of cases of metastasis on the basis of primary site

\begin{tabular}{|l|c|}
\hline Site & No. of Cases \\
\hline Breast & 9 \\
\hline Gastrointestinal tract & 4 \\
\hline Ovary & 3 \\
\hline Thyroid & 2 \\
\hline Lung & 2 \\
\hline Cervix & 1 \\
\hline Tonsil & 1 \\
\hline Prostate & 1 \\
\hline Plasmacytoma & 1 \\
\hline Total & 24 \\
\hline
\end{tabular}

Reactive lymphadenitis and suppurative lymphadenitis were noted in 11 cases each.
Reactive lymphadenitis was predominantly noted in $3^{\text {rd }}$ and $4^{\text {th }}$ decade of life with female predominance. (Table 3 and 4)

Suppurative lymphadenitis (Figure 5) with predominant polymorphonuclear cell population and necrotic debris was noted commonly in male patients, constituting 7 cases out of 11 cases.

Granulomatous inflammation (Figure 6) with epithelioid granuloma, Langhans giant cells and necrosis were noted in 8 cases but only 1 case showed acid fast bacilli on staining with $20 \%$ Ziehl Neelson stain (Figure 7).

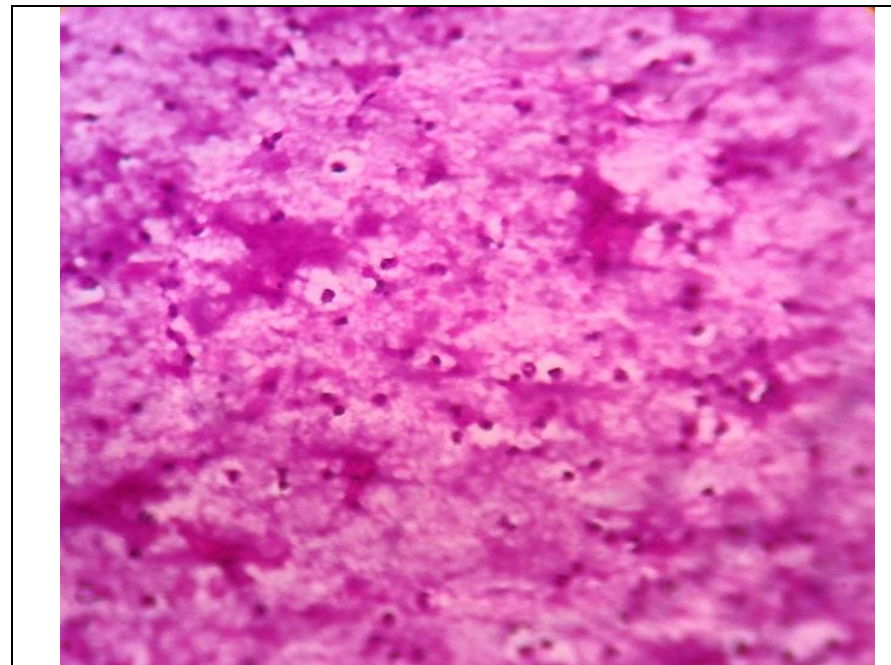

Figure 5. Photomicrograph of FNAC SCLN showing suppurative aspirate with inflammatory cells ion necrotic background (100 x, H\&E)

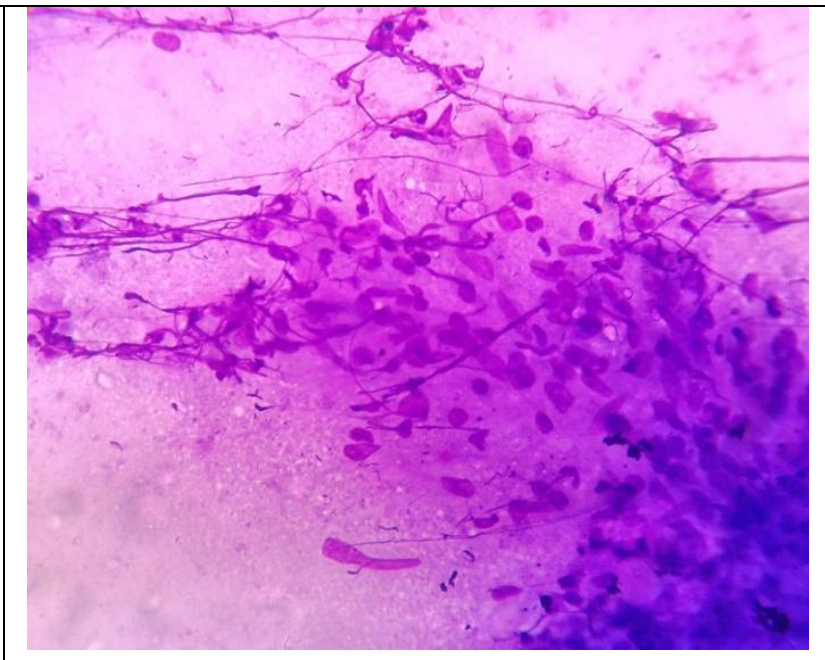

Figure 6. Photomicrograph of FNAC SCLN showing epithelioid cells forming granuloma (100x, H\&E)

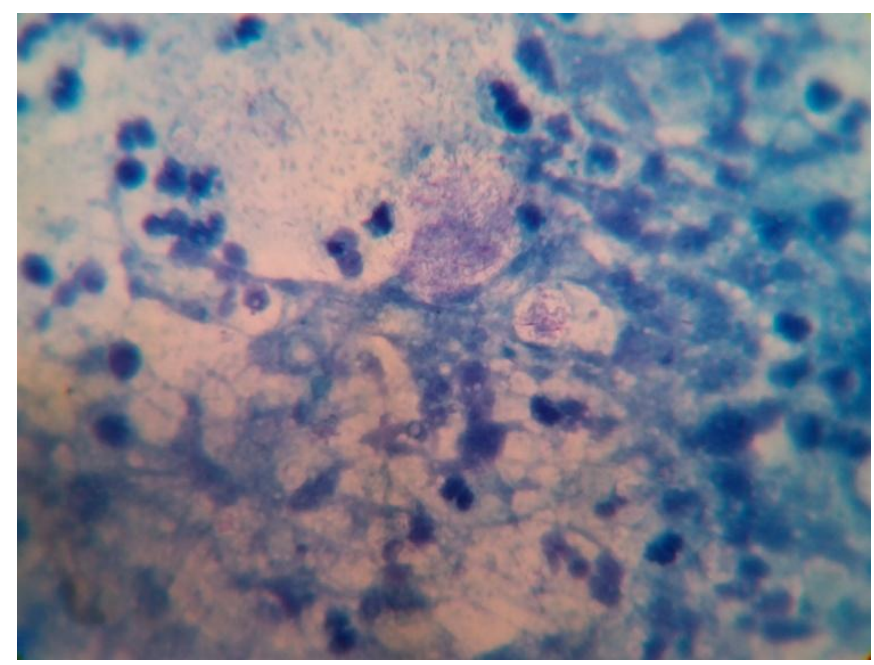

Figure 7. Photomicrograph showing Acid Fast Bacilli in lymph node aspirate.(1000x, 20\% ZN ) 
Table No. 6: Distribution of cases on the basis of laterality

\begin{tabular}{|l|c|c|}
\hline & Right & Left \\
\hline Reactive & 8 & 3 \\
\hline Acute Suppurative & 6 & 5 \\
\hline Tuberculosis & 6 & 2 \\
\hline Metastatic & 10 & 14 \\
\hline Breast & 4 & 5 \\
\hline Gastrointestinal tract & 1 & 3 \\
\hline Ovary & 1 & 2 \\
\hline Thyroid & 2 & 0 \\
\hline Lungs & 1 & 1 \\
\hline Tonsil & 0 & 1 \\
\hline Cervix & 0 & 1 \\
\hline Plasmacytoma & 0 & 1 \\
\hline Prostate & 1 & 0 \\
\hline Total & 30 & 24 \\
\hline
\end{tabular}

\section{Discussion}

Supraclavicular lymphnodes are easily palpable when enlarged and are common site for metastasis deposits from malignancies. ${ }^{9}$

Enlarged supraclavicular lymphnode can be the first clinical manifestation of underlying malignancy. ${ }^{10}$ FNAC being a simple, minimal invasive and rapid diagnostic procedure it is routinely used as investigation of choice for assessing supraclavicular lymphadenopathy especially in cases of metastasis. ${ }^{11}$

Importance of FNAC in diagnosis of supraclavicular lymphadenopathy has been highlighted by many authors in their study. ${ }^{6,12-15}$

Metastatic tumours were the most common cause of supraclavicular lymphadenopathy in the present study $(24 / 54 ; 44.44 \%)$, similar findings were reported by other authors in their study. ${ }^{1,16,17}$ Among the metastasis lesion, adenocarcinoma was the most common metastatic tumor which is in concordance with the findings by Laishram.et.al in their study. ${ }^{18}$ Primary sites noted in our study were Breast, Gastrointestinal tract, Ovary, Thyroid, Lung, Prostate, Tonsil, Cervix and Plasmacytoma.

Authors have reported metastatic adenocarcinoma in supraclavicular lymphnode from Breast ${ }^{10}$, Gastro-intestinal Tract ${ }^{19}$, 20. Lungs ${ }^{21}$, Prostate ${ }^{22}$, Ovary ${ }^{1}$ Thyroid ${ }^{1}$.Metastatic squamous cell carcinoma (SCC) was noted in 3 cases with one case each from tonsil, lung, and cervix. Similar findings about metastatic SCC from lungs ${ }^{13}$ and cervix ${ }^{23}$ have been reported.

Studies by other authors have shown that lymphoid malignancy forms a small part of the tumors in cases of supraclavicular lymphadenopathy. ${ }^{1,6}$ In our study we did not have any case of lymphoid malignancy presenting as supraclavicular lymphadenopathy.

Tuberculous lymphadenitis was cause of supraclavicular lymphadenopathy in $14.8 \%$ of cases which is similar to the findings by Gupta et.al ${ }^{17}$ Nasuti JF et $\mathrm{al}^{6}$ reported an incidence of $2 \%$ whereas Adhikariet $\mathrm{al}^{1}$ in this study reported incidence of $41.6 \%$.

\section{Conclusion}

The often asked question to pathologist is whether fine needle cytology is still useful in the era of advanced imaging, ancillary techniques or not. The cytological diagnosis in every case may not be possible. FNAC can diagnose cases like Tuberculous Lymphadenopathy. Were commend to FNAC as an important diagnostic procedure in patients above the age of 45 years with supraclavicular lymphadenopathy which is safe, cost effective, well tolerated, and minimally invasive with no reported complications. This study has tried to enlighten the importance of FNAC in cases with supraclavicular lymphadenopathy.

\section{Acknowledgement}

Thanks to Miss Shruti V. Karambelkar for her valuable inputs during the preparation of manuscript.

\section{References}

1. Adhikari RC, Jha A, Sayami G, Shrestha S, Sharma SK. Fine needle aspiration cytology of palpable supraclavicular lymph nodes. J Pathol Nepal 2011;1:812.

2. Hsu C, Leung BS, Lau SK, Sham JS, Choy D, Engzell U. Efficacy of fine needle aspiration and sampling of lymph nodes in 
1,484 Chinese patients. Diagn Cytopathol 1990:6:1549.

3. Haque MA, Talukder SI. Evaluation of fine needle aspiration cytology (FNAC) of lymph node in Mymensingh. Mymensingh Med J 2003;12:335.

4. Malakar D, Jajoo IL, Swarup K, Gupta OP, Jain AP, Poflee VW. A clinical evaluation of fine needle aspiration cytology in the diagnosis of lymphadenopathy. Indian J Tuberc 1991;38:17.

5. Rakshan M, Rakshan A. The diagnostic accuracy of fine needle aspiration cytology in neck lymphoid masses. Iranian J Pathol 2009; 4:14750.

6. Nasuti JF, Mehrotra R, Gupta PK. Diagnostic value of fine-needle aspiration in supraclavicular lymphadenopathy: a study of 106 patients and review of literature. DiagnCytopathol2001;25:351-5.

7. Morgenstern L. The Virchow-Troisier node: a historical note. Am J Surg 1979; 138:703.

8. Heerde PV, Miliauskas J, Field A. Lymph nodes. In: Orell SR, Sterrett GF, Whitaker D, editors. Fine Needle Aspiration Cytology. 4 th ed. New Delhi: Elsevier; 2010. p. 83124.

9. Sriwatanawangsa V, Cardoso R, Chang P. Incidence of malignancy inperipheral lymph node biopsy. Am Surg1985;51:58790.

10. Moore KL. The thorax. In: Clinically Oriented Anatomy. 2 nd ed. Baltimore: Williams and Wilkins; 1985. p. 49148.

11. Ghartimagar D, Ghosh A, Ranabhat S, Shrestha MK, Narasimhan R, Talwar OP. Utility of fine needleaspiration cytology in metastatic lymph nodes. J Pathol Nepal 2011;1:925.

12. Gupta RK, Naran S, Lallu S, Fauck R. The diagnostic value of fine needle aspiration cytology (FNAC) in the assessment of palpable supraclavicular lymph nodes: a study of 218 cases. Cytopathology 2003;14:201-7.

13. Carson HJ, Candel AG, Gattuso P, Castelli MJ. Fine-needle aspirationof supraclavicular lymph nodes. Diagncytopathol 1996;14:216-20.

14. Cervin JR, Silverman JF, Loggie BW, Geisinger K. Vichow's node revisited: analysis with clinicopathologic correlation of 152 fine needle aspiration biopsies of supraclavicular nodes. Arch Pathol Labmed 1995;119:727-30.

15. McHenry CR, Cooney MW, Slusarczyk SJ, Khiyami A. Supraclavicular lymphadenopathy: the spectrum of pathology andevaluation of fine-needle aspiration biopsy. Am Surg1999;65:742-6.

16. Mitra S, Ray S, Mitra PK. Fine needle aspiration cytology of supraclavicular lymph nodes: Our experience over a three yearperiod. J Cytol 2011;28:10810.

17. Gupta N, Rajwanshi A, Srinivasan R, Nijhawan R. Pathology of supraclavicular lymphadenopathy inChandigarh, north India: An audit of 200 cases diagnosed by needle aspiration. Cytopathology 2006; 17:946.

18. Laishram RS, Devan R M, Laishram S, Sharma DC. Pattern of disease in palpable supraclavicular lymph node: Acytopathological perspective. J Med Soc 2012;26:163166

19. Metayer P, Antonietti M, Oumrani M, Hemet J, Lemoine F, Basuyau J. Metastases of a gastric adenocarcinoma presenting as colonic polyposis. Report of a case. Dis Colon Rectum 1991;34:622-3.

20. Khorsand J, Katz RL, Savaraj N. Malignant carcinoid of the pancreas: a cytologic ultrastructural and immunocytochemical study of a case diagnosed by fine-needle aspiration of a supraclavicular lymph nodemetastasis. DiagnCytopathol1987;3:222-7. 
21. Sugama Y, Kitamura S. Ultrasonographic evaluation of neck and supraclavicular lymph nodes metastasized from lung cancer. Int Med1992;31:160-4.

22. McMenamin PG, Anderson JD, Baker JJ. Prostatic carcinoma presenting with neck metastases. J Otolaryngol1989;18:119-24.

23. Yao ZH, Wu AR. Supraclavicular lymph node metastasis from carcinoma of the uterine cervix after radiotherapy - analysis of 219 patients. Chung - Hua Chung Liu TsaChih1988;10:230-2. 